\title{
Attending to the logics of inquiry
}

\author{
Rachel H. Ellaway ${ }^{1}$
}

Accepted: 29 March 2021

(C) The Author(s), under exclusive licence to Springer Nature B.V. 2021

In an earlier editorial I asked that we be more attentive to the dynamics and logics of mixed methods research (MMR) (Ellaway, 2020). Central to my argument then was the need to be explicit about the logics of different MMR designs in terms of their intents, assumptions, and inferences. I return to the issue of logics of inquiry in this editorial to reflect on the logics of scholarly inquiry in general, including, but not limited to, research studies. I use the term 'logics' rather than 'logic' because there is no one uniform, overarching, or common logic in the frames and practices of inquiry in our field. Indeed, there are often different logics used in different studies and even within a single study. For instance, different studies might explore medical school admissions but use different logics in how they frame their study goals, in how they conceptualize the problem space, and/or in how they frame their research questions, and so on.

Although they have not been particularly visible in health professions education scholarship, logics are a topic of discussion elsewhere in the social sciences. For instance, in the context of social and political theory, Glynos and Howarth (2007) proposed that "the logic of a practice comprises the rules or grammar of the practice, as well as the conditions which makes the practice both possible and vulnerable". In the context of organizational research Jones et al. proposed that the logics of a methodology reflect the structural theory of that methodology (Jones et al. 2013). In the context of qualitative research methodologies Silverman proposed that the logics of a methodology are reflected in its structures, purposes, and assumptions. (Silverman, 1997).

Logical arguments are based on conclusions supported by premises. For instance, although these two logics are similar, the premises and therefore the conclusions differ:

[participation in a research study is voluntary] +[we need at least 20 participants] + [we had 50 volunteers] therefore [this study used a combination of convenience and purposive (or random) sampling]

[participation in a research study is voluntary] +[we need at least 20 participants] + [we had 20 volunteers] therefore [this study only used convenience sampling]

More importantly, the implications of one logic may have implications for others. While both of these logics are defensible, the first might be considered more robust and therefore

Rachel H. Ellaway

rachel.ellaway@ucalgary.ca

1 Department of Community Health Sciences and Office of Health and Medical Education Scholarship, Cumming School of Medicine, University of Calgary, Calgary, AB, Canada 
the subsequent analyses and inferences might also be considered more robust and therefore more defensible.

Defensibility is the broad standard for the quality of academic work. Papers published in academic journals (such as AHSE) go through a system of rigorous peer review, as do grant applications, promotions, and job applications. Arguably, there are parallels in medical school admissions, appeals committees, and competency committees. Defensibility of academic work depends to a great extent on judgment rather than rigorous proof, although some research paradigms, particularly those with a formal logical component such as mathematics, can yield to some extent to more formal tests of proof and validity.

In formal deductive logic, if the premises are true then the conclusion drawn from them must also be true; this is logical validity. A logical argument is also considered 'sound' if its premises are true and the argument as a whole is valid. (Lee, 2017). However, we rarely deal with absolutes in health professions education (HPE) and the standard for logical reasoning is often inductive. In an inductive logic the more likely that premises are true then the more likely it is that the conclusion is true. From a deductive perspective, all inductive logic is invalid because it cannot be perfectly valid. Cogency is a term used for an equivalent standard to validity in inductive logic; an inductive argument is cogent if its premises are "acceptable, relevant to, and sufficient for its conclusion". (Johnson \& Blair, 1993) This means that "in a good inductive argument, the truth of the premises provides some degree of support" (Hawthorne, 2021). Given the complexities and limitations of social science, logics in HPE research might be expected to be based more on inductive than deductive logics.

Formal inductive logic is typically equated with Bayesian probabilistic logic, with its formal language and practices. While these kinds of analyses might have some value in HPE research (and I would be interested to see examples) they are clearly not a part of our current repertoire, nor can I immediately think of a compelling rationale for them to become so. Our field seems better aligned with 'informal logic', which "does not rely on the chief analytic tool of formal deductive logic, the notion of logical form ... but that does not mean this logic is non-formal in the sense that it abandons reference to standards, criteria or procedures." (Johnson \& Blair, 2000) I would argue that the logics of HPE research primarily conform to informal logic because of their entanglements with dialectics (comparing logics) and rhetorical reasoning (reasoning based on exposition, description, narration, and argumentation). After all argumentative logic (within the frames of informal logic) is the primary medium for scholarly communications (such as those we publish in AHSE). The bona fides of a paper, the study it reports on, and the team who conducted the study and wrote the paper are (or should be) presented logically so as to inform any inferences made about the quality and authority of the work being presented.

Having established (using informal logics) that logics are present and relevant in HPE research, let me turn to the different kinds of logics we see in academic writing, starting with the purposes of research. Lingard's 'problem-gap-hook' (PGH) (Lingard, 2015) frame for establishing the purposes of a body of inquiry is a case in point. The logic of [in this problem area] + [we know this, but we don't know that] + [filling the gap is important/useful/necessary] therefore [we will conduct research to help fill the gap] is a compelling one. PGH is deductive in that it goes from generalities to specifics and it anchors on addressing an important deficit, to that end its logics are corrective, remedial, and/or normative. There are other logics of purpose though, such as exploiting opportunities, exploring possibilities, or even simply pursuing curiosity. How strong these logics are in terms of how persuasive or defensible they are (or are perceived to be) will contribute to the aggregate logics for the study as a whole. 
Logics are also present in our assumptions in undertaking acts of inquiry. For instance, should a study treat learners as undifferentiated units of instruction, group them according to different categories, or treat them all as unique? Are we interested in a particular aspect of an individual (their mind, their reactions, or their physiological state), or the whole person, or groups of persons, or persons from some superordinate category such as 'all dietetic interns'? Are we interested in single moments, or activities, or sessions, or sequences of events, potentially stretching over extended periods of time? Each of these has implied logics and in turn has implications for other logics of particular acts of inquiry.

We should also consider how different combinations of logics have different implications in study designs. Simply contrasting the logics of what is being explored with the logics of how it is being explored can be illuminating and generative-see Table 1. We might also consider the logics of the constructs we use. For instance, what are the logics of the connections between measurable variables and latent constructs (such as competence or compassion)? When (in realist inquiry) is something a context, a mechanism, or an outcome? What are our assumptions about the nature of causality? (see Pawson, 2008) Do our categories have taxonomic (exclusive) or faceted (intersectional) logics? How do we deal with the logics of emic and etic positionalities in acts of inquiry? What are the logics of comparison in the use of control groups or in the use constant comparative methods? What are the different logics of sampling (random, diversity, theoretical, convenience)? What are the logics of generalization (similarity, probability, utility, prediction, explanation, typicality, atypicality)? What are the logics of evidence (probability, plausibility)? (Thistlethwaite et al. 2012) These kinds of logics are critical in appraising the scientific literature.

Logics are not limited to acts or frames of inquiry. Indeed, logics are present across much of HPE and they therefore also deserve consideration. For instance, what are the different logics of the social contract or social accountability? Some logics focus on workforce (providing needed healthcare professionals), some logics focus on equity of access to the professions, others on community involvement, and yet others on the input of a community to educational and scholarly planning. Some models of social accountability are deductive (follow these principles in order to meet some threshold of accountability) while others are inductive (build meaningful relationships in whatever configuration makes sense to the parties involved). Similarly, we might consider the logics of assessment; summative or formative, episodic or continuous, criterion- or norm-referenced, and so on. It would be particularly interesting, I think, to unpack the logics of multi-dimensional constructs such as programmatic assessment, competency-based education, simulation, or problem-based learning.

This brings me to the consideration of systems of logics; how do different logics that apply to the parts of a study contribute to the combined logics in a study, across multiple

Table 1 Combining different logics of what kinds of data are being reviewed and the different logics of how the data might be reviewed can be used to create a contingency table where potentially nine distinct review methodologies might be mapped out (A-J)—abstracted from Kelly et al. (2018)

\begin{tabular}{llll}
\hline & $\begin{array}{l}\text { Exclusively } \\
\text { quantitative } \\
\text { data }\end{array}$ & $\begin{array}{l}\text { Mixed (quantitative } \\
\text { and qualitative) data }\end{array}$ & $\begin{array}{l}\text { Exclusively } \\
\text { qualitative } \\
\text { data }\end{array}$ \\
\hline Exclusively quantitative review methods & A & B & C \\
Mixed (quantitative and qualitative) review methods & D & E & F \\
Exclusively qualitative review methods & G & H & $\mathrm{J}$ \\
\hline
\end{tabular}


studies, or across a domain of inquiry? Despite the differential rhetoric of paradigms, many logics apply across paradigms, so we can infer that there is a loose coupling between most logics of inquiry and that they cannot therefore be assumed to be exclusive to one domain or to always travel in fixed configurations. Moreover, given the tendency to adapt methods and methodologies in an applied field such as ours, a clear articulation of a study's logics could prove essential in establishing the cogency of a hybrid approach and to deal with concerns such as mixed-methods commensurability and inference.

Logics also have the potential to assist with study design. After all, research is designed; it is intentional, directed, planned. To that end logics form much of the syntax of research design processes. Logics can also be active components in a methodology and not just the glue that holds a methodology together. For instance, identifying logics of research papers as part of a systematic review could help to appraise whether erstwhile similar or dissimilar studies have as much in common as it might at first appear or perhaps more than might be assumed based on other criteria. Attention to logics could be also be a domain of inquiry in its own right, for instance in appraising the role of logics in the morphogenesis of methods and methodologies. (Apramian et al. 2017).

This is an editorial rather than an extended treatise. I have only outlined some of the domains of logics we might usefully consider. I will leave the consideration of other logics, such as those related to theory, methods and methodologies, and analyses and syntheses, to others to explore. I hope, however, that this brief tour through logics has made the point that they are not just a matter for philosophers or those interested in metascholarship. All inquiry, all scholarship has logics; they are implied even if they are not explicitly articulated. I am not asking you to become deeply engaged in logical reasoning nor to be competent in the intricacies of the various domains of formal logical reasoning (although it wouldn't hurt). But I would ask, given that your work and your use of other people's work does depend on logics, that you should be attentive to them and their consequences. Being more mindful of the logics of inquiry can help to anchor the overall logic of a study, to situate it within the multitude of possible logics of inquiry, and to make apparent both for critique and instruction the logical skeletons upon which acts of inquiry are hung. I invite you to use this as a lens through which to read the papers in this issue of AHSE and in your participation in the field of health professions education as a whole.

\section{References}

Apramian, T., Cristancho, S., Watling, C., \& Lingard, L. (2017). (Re)Grounding grounded theory: A close reading of theory in four schools. Qualitative Research, 17(4), 359-376.

Ellaway, R. (2020). Mixed methods, crimes, and misdemeanours. Advances in Health Sciences Education., 25(4), 777-779.

Glynos, J., \& Howarth, D. (2007). Logics of critical explanation in social and political theory. (p. 136). Routledge.

Hawthorne, J. (2021). Inductive logic. In: E.N. Zalta (Ed.) The Stanford encyclopedia of philosophy (Spring 2021 Edition). https://plato.stanford.edu/archives/spr2021/entries/logic-inductive/

Jones, C., Boxenbaum, E., \& Anthony, C. (2013). The immateriality of the material in institutional logics. Research in the Sociology of Organizations., 39, 51-75.

Johnson, R. H., \& Blair, J. A. (1993). Logical self-defence. (3rd ed.). McGraw-Hill Ryerson.

Johnson, R. H., \& Blair, J. A. (2000). Informal logic: An overview. Informal Logic, 20(2), 93-107.

Kelly, M., Ellaway, R. H., Reid, H., Ganshorn, H., Yardley, S., Bennett, D., \& Dornan, T. (2018). Considering axiological integrity: A methodological analysis of qualitative evidence syntheses and its implications for health professions education. Advances in Health Sciences Education., 23(4), 833-851. 
Lee, S. (2017). Logic: A complete introduction. . Hodder \& Stoughton.

Lingard, L. (2015). Joining a conversation: The problem/gap/hook heuristic. Perspectives on Medical Education, 4(5), 252-253.

Pawson, R. (2008). Causality for beginners. In NCRM research methods festival 2008, UK. http://eprints. ncrm.ac.uk/245/

Silverman, D. (1997). The logics of qualitative research. In G. Miller \& R. Dingwall (Eds.), Context and method in qualitative research. (pp. 13-25). Sage.

Thistlethwaite, J., Davies, H., Dornan, T., Greenhalgh, T., Hammick, M., \& Scalese, R. (2012). What is evidence? Reflections on the AMEE symposium, Vienna, August 2011. Medical Teacher, 34(6), 454-457.

Publisher's Note Springer Nature remains neutral with regard to jurisdictional claims in published maps and institutional affiliations. 